\title{
Incentives to increase patient satisfaction: Are we doing more harm than good?
}

\author{
Jay Detsky MD PhD, Randi Zlotnik Shaul LLM PhD
}

$\mathrm{O}$ ver the past several years, a growing trend in health care has been to adopt a consumer-oriented philosophy to provide patient-centred care and maximize patient satisfaction. This focus on the patient experience has led to a substantial increase in peerreviewed literature using patient satisfaction as a metric. ${ }^{1}$

The Ontario government, under the Excellent Care for All Act 2010, has legislated that all hospitals perform yearly surveys of patient satisfaction and use the results to guide their qualityimprovement plans. These plans are used to determine quality-improvement targets; by law, executive compensation must be linked to the achievement of those targets. In the United States, The Affordable Care Act includes the provision that up to $1 \%$ of Medicare reimbursements be redirected from hospitals with low patient satisfaction scores to those with high scores. ${ }^{2}$

The push to deliver patients who report being satisfied is changing how the principle of patient autonomy is interpreted; self-determination (the patient's right to accept or reject proposed treatments) in some contexts is evolving into patientdirected care (where patients demand specific tests or treatments). The struggle between true patient-centred care (patient engagement within the process of evidence-based medicine) and patient-directed medicine is readily apparent in the internet age where patients increasingly have specific requests for care based on their own information gathering, which may not be evidencebased or clinically warranted. In our attempts to increase patient satisfaction, we may be establishing frameworks that actually cause harm.

\section{Satisfaction and outcomes}

Are we satisfying patients at their own peril? A substantial debate has arisen in the literature regarding whether improved patient-satisfaction scores are linked to improved outcomes. The most recent study involving a national sample of American patients showed that the highest level of patient satisfaction is associated with greater prescription drug costs and overall health care expen- ditures and $26 \%$ higher overall mortality compared with those with the lowest levels of satisfaction, even after adjusting for sociodemographics, medical comorbidities and previous health expenditures. ${ }^{3}$ This study is supported by earlier data showing that patient satisfaction had no correlation with technical quality of care (i.e., the use of health services according to standards of care). ${ }^{1.45}$

These studies all used survey-based ratings of patients' self-reported overall satisfaction with their health care encounters. In contrast, Manary and colleagues ${ }^{6}$ argue that appropriately designed patient-experience surveys provide robust measures of quality and have been linked with better outcomes, particularly when surveys are completed in a timely manner after the encounter and when satisfaction is derived from questions regarding interactions with the entire health team as opposed to with physicians alone. However, the overwhelming evidence shows that satisfaction has no correlation to quality of care.

\section{Dissecting the data}

There are several cautions related to the data derived from patient satisfaction surveys. Research suggests that patient-satisfaction is greatly influenced by patient age, income, anxiety, education and comorbidity. ${ }^{7}$ These confounding variables must be adjusted for when using satisfaction as a metric. In addition, definitions of satisfaction vary across studies, ${ }^{1,3}$ leading to interpretative difficulties. Furthermore, the time between the health care encounter and the response to the questionnaire can vary, limiting the generaliz-
Competing interests: None declared.

This article has been peer reviewed.

Correspondence to: Jay Detsky, jay.detsky@mail.utoronto.ca

CMAJ 2013. DOI:10.1503 /cmaj.130366 
ability of results. Finally, in Ontario, the surveys used by hospitals to develop quality improvement metrics are administered by a private company, with no publicly available information regarding survey validation or power.

\section{Discretionary care and pseudodisease}

How could increased patient satisfaction lead to poor outcomes? Fenton and colleagues ${ }^{3}$ speculate that the use of discretionary care (i.e., medical interventions or treatment for which there is no proven benefit) is increasing and may lead to iatrogenic harm owing to overtreatment. Fisher and $\mathrm{Welch}^{8}$ have summarized numerous specific examples in which increased medical care led to harm.

An increase in investigations leads to increased potential for detecting and treating what has been referred to as "pseudodisease"; 9 that is, disease that would never otherwise have been known to the patient and would have remained asymptomatic. However, patients tend to be highly satisfied when an initially positive discretionary test result is eventually proven to be a false-positive, thus reaffirming their health, or leads to the early detection and curative treatment of pseudodisease that they falsely believed would have been detrimental. Furthermore, many physicians have substantial incentives to provide discretionary care through institutional pressures, reimbursement schemes, decreased liability and the desire to avoid bad ratings on consumer websites. Finally, patient satisfaction may also be decreased by honest and frank discussions with patients about their lifestyles and habits, including topics such as obesity, smoking and substance abuse. If physicians' goals of care are weighted too heavily toward patient satisfaction, then an incentive may exist to discourage lifestyle interventions and discussions of preventive care. Sirovich ${ }^{9}$ has argued that this constitutes a positive feedback loop whereby both physicians and patients have incentives to seek out additional discretionary care. We must ask whether this feedback contributes to inappropri- ate and unsustainable use of the health care system and the inequitable distribution of resources.

\section{Looking forward}

The recent data regarding patient satisfaction should be a springboard to further study the best way to define satisfaction, how it is properly measured and whether its improvement is truly beneficial or detrimental to one's health. In the meantime, research and quality improvement plans should focus on satisfaction data that are balanced with objective measures of quality of care or outcomes. Satisfaction surveys and a critical analysis of the patient experience should continue to be sought to identify opportunities for improvement. Finally, limitations need to be placed on the incentives for physicians and hospitals to increase discretionary care, including tempering the financial ramifications of patients' ratings of overall satisfaction until we better understand the links between satisfaction and potentially harmful patient-directed care.

\section{References}

1. Lee DS, Tu JV, Chong A, et al. Patient satisfaction and its relationship with quality and outcomes of care after acute myocardial infarction. Circulation 2008;118:1938-45.

2. Geiger NF. On tying medicare reimbursement to patient satisfaction surveys. Am J Nurs 2012;112:11.

3. Fenton JJ, Jerant AF, Bertakis KD, et al. The cost of satisfaction. Arch Intern Med 2012;172:405-11.

4. Chang JT, Hays RD, Shekelle PG, et al. Patients' global ratings of their health care are not associated with the technical quality of their care. Ann Intern Med 2006;144:665-72.

5. Rao M, Clarke A, Sanderson C, et al. Patients' own assessments of quality of primary care compared with objective records based measures of technical quality of care: cross-sectional study. BMJ 2006;333:19-22.

6. Manary MP, Boulding W, Staelin R, et al. The patient experience and health outcomes. N Engl J Med 2013;368:201-3.

7. Rahmqvist M. Patient satisfaction in relation to age, health status and other background factors: a model for comparisons of care units. Int J Qual Health Care 2001;13:385-90.

8. Fisher ES, Welch HG. Avoiding the unintended consequences of growth in medical care. JAMA 1999;281:446-53.

9. Sirovich BE. How to feed and grow your health care system. Arch Intern Med 2012;172:411-3.

Affiliations: Department of Radiation Oncology (Detsky), University of Toronto; Bioethics Department (Detsky, Shaul), The Hospital for Sick Children; Department of Pediatrics (Shaul), University of Toronto, Toronto, Ont.

Contributors: Jay Detsky drafted the article. Both authors revised the article critically for important intellectual content and approved the final version submitted for publication. 